\title{
Bioproducts from Potatoes. A Review
}

\author{
Vivita PRIEDNIECE ${ }^{1 *}$, Kriss SPALVINS ${ }^{2}$, Kaspars IVANOVS ${ }^{3}$, Jelena PUBULE $^{4}$, \\ Dagnija BLUMBERGA ${ }^{5}$

\section{${ }^{1-5}$ Institute of Energy Systems and Environment, Riga Technical University, Azenes iela 12/1, Riga, LV-1048, Latvia}

\begin{abstract}
The increasing amount of food waste througout the world is becoming a major problem for waste management plants. The food waste produced amounts to 1.3 million tons a year. This is a resource that could be used for production of new products. Decreasing fossil resources and a rapidly growing population lead to the necessity to produce more food and to replace existing with new materials ones that are biological and produce little effect on environment. Bioeconomy is a method that can help achieve production of value-added products that use local resources and waste to manufacture products efficiently. In this article, we are looking at possibilities to use potatoes for production of new materials, such as bioplastics, antioxidants, proteins, instead of their conventional use for food production. We have studied potato components, extraction technologies and summed up possible directions for development for new products, looking at the use of processing waste as a raw material.
\end{abstract}

Keywords - Bioplastics; biotechnologies; pharmacy; potatoes; value-added bioproducts

\section{INTRODUCTION}

Potatoes are one of the main food sources in the world, with 100-180 different species and thousands of varieties over the world. Potatoes are an important source of nutrients for humans and animals, but their full potential for extended use is yet to be examined. Now they are mostly used in food production because of their short growing time and potential for use, as well as their ability to adapt to different climate conditions. It is an important characteristic, because potato tubers contain starch, proteins, ascorbic acid, carbohydrates, minerals, vitamins and fibre, making it a nutrient with low fat content. Preservation of potatoes for consumption can be achieved by putting fully grown potatoes in the appropriate environment (average storage temperature, dark room) and making sure they are kept away from possible harm, such as pressure, physical injury [1]-[3].

Potatoes around the world can be divided not only by species and variety, but also by colour. Most potatoes are in different shades of yellow, but there are also red and blue (purple) fleshed varieties. These colourful varieties contain larger amounts of phytonutrients, as well as anthocyanin (that gives them specific colour), when compared to yellow potato species. These components provide an opportunity to use potatoes as a natural colorant for food, not to mention possible use for health benefits, including healing of wounds, caused by burns [4].

Most waste from potato production is made up by peel and damaged potatoes. This waste is mainly used for animal feed or bio-fuels production, however, they contain large amounts of valuable compounds, which make it possible to use them in pharmacy, food production, medicine applications which is when bioeconomy principles are taken into account. Bioeconomy is a science-based method that analyses the rational and effective use of local resources to create new, value-added products for the existing market [5]. In this article, we are looking at unconventional ways for use of potatoes and their peel to obtain different products and compounds

* Corresponding author.

E-mail address: vivita.priedniece@rtu.lv 
that can be used for innovative products in the market, by implementing novel technologies with higher efficiency then conventional ones.

\section{Bioresource - Potatoes}

Potatoes have antioxidant characteristics that give them the ability to control cholesterol levels and may provide a possible use as a cancer preventive agent in the future. Potatoes that are colourful contain a lot of phytochemicals as well, like carotenoids, polyphenols (flavonoids (anthocyanins), phenolic acids, tannins), pectins that can be used for reduction of chronic illnesses [6], [7].

If we look at potato content and their possible use in detail, it is important to consider, that potatoes contain proteins that can serve as food ingredients, due to high quality and nutritional advantages, as well as important amino acid index. These proteins are non-allergenic and can be used in the manufacture of food products for any taste, such as gluten-free products, cheese and wine must. There are three types of potato proteins: patatin, protease inhibitors and different proteins with high molecular weight [6], [7]. Even though the protein content in potatoes is approximately $2 \%$ when they are fresh, these amounts increase during the drying process. The total protein content in dried potatoes is equal to one for cereals, with higher nutritional quality [8].

The characteristic mechanical properties for agricultural crops are: viscosity, basic mechanical and elastic behaviour, texture analysis, that is caused by stress, strain and time. The most important part of a potato, that is also the one used for consumption, is tuber, the skin strength of which is essential, as it leaves an effect on possible damages to the crop. It is proved that a bigger load during storage time can create long term damage, such as black spots, leading to decreased overall supply [9].

The biggest threat for potatoes, apart from physical injuries, is disease, and the most essential disease for these plants are late and early blight. Late blight, also known as Phytophthora blight, is a decease caused by infestants of the same name or $P$. capsici. These organisms are in close relation to algae, even though they can be seen as fungus on potatoes [10].

Sanchez Maldonado, et al. [11] aimed to use potato peels for phenolic acid and glycoalkaloids extraction and create a sustainable extraction method using food grade solvents. As potatoes are one of the main food sources used by humans, there are a lot of leftovers from production that make up between $50 \%$ and $60 \%$ of the raw material. The biggest part consists of peels. So far, potato peels have not been used for production of value-added products, but it is possible. This resource has a lot of valuable components, such as phenolic compounds and glycoalkaloids, that can be obtained and after treatment used in food and pharmacy industries. These compounds have antibacterial and antioxidant activities that gives an opportunity to use them as additives in different foods and packing materials [11].

Potential products that can be produced from potato peels are biodiesel and biomanure, biogas (methane), lactic acid, glycoalkaloids, phenols and biosorbent to remove toxins from water. The selection of peels used for production is dependent on its contents. In research by Friedman, et al. [13] different potato varieties, with a focus on phenolic content concentration in peels have been studied. The study might serve as a useful tool for the choice of materials for production. Other authors have also reported that peels might be a useful feed for animals, such as chickens, to provide them with better nutrition at low costs. Peels serve as a protective layer for potatoes, so it might be useful for the protection of other organisms as well. It has to be noted that peel extract should be obtained in an alkaline environment with approximately $9 \mathrm{pH}$ [14], [15]. 
To obtain the compounds mentioned previously, it is important to collect information on the most suitable treatment technologies for extraction which has been done in the next section of the article.

\section{BioteChNOLOGIES}

The most widely used extraction methods for phenols from plants use organic solvents that are harmful for the environment, such as methanol, acetone, chloroform/methanol mixtures. Less harmful alternatives for extraction are water and ethanol or water/acetic acid mixtures, especially for glycoalkaloid extraction. As there is no simultaneous method for glycoalkaloid and phenolic acid recovery, a new method has been developed using acidified water/ethanol based solvents to extract compounds that are suitable for use in the food industry, therefore decreasing created waste and effects on the environment [10], [16].

Extraction of phenols can be done from plant samples in different phases. Before extraction, samples are processed with mills or a grinder to make the sample homogenous. In most cases, the sample needs to be dried before further treatment, using air or freeze-drying methods. It is not possible to obtain only phenols from the plant, usually it is a mix of phenols and non-phenolic substances, and thus further treatment to remove any unwanted components from the mixture has to be made. One of the key parts of the extraction process is the choice of solvent. Usually methanol and ethanol are used, as ethanol is more suitable for phenol extraction meant for human consumption. Other solvents used for extraction include acetone, ethyl acetate and their combinations in a variable mix with water [17].

Other parameters that effect extraction are duration time and applied temperature, for example, temperatures above $70{ }^{\circ} \mathrm{C}$ are not appropriate for anthocyanin extraction, as this causes decomposition of these compounds. Conventional extraction methods, like soxhlet extraction are inefficient, time consuming and harmful to the environment, therefore there is a need to look at newer technologies [17].

Antioxidant extraction from potato peels has been studied in [18] as well. Authors were looking for optimisation options for extraction conditions (temperature, duration time, used concentration of ethanol) using a surface response methodology, when ethanol serves as an environmentally friendly alternative to organic solvents. Results of this study showed that potato peel has great antioxidant abilities, which can be used to limit oxidation [18].

Other technologies that have been used for potato peel waste treatment are: pressurised liquid, subcritical water, supercritical $\mathrm{CO}_{2}$, ultrasound assisted, accelerated solvent and microwave assisted extraction. These methods have high efficiency, with variable costs and, in some cases, decreased or no use of organic solvents that leave a negative effect on the environment and can become a toxic threat. A method that can be used for obtaining potato pectin is ultrasonic treatment that improves its antioxidant activity. It could serve as a new, cheap, effective and simple method for pectin depolymerisation that could be transferred to other polymers [17], [19]-[22].

Ultrasound-assisted extraction (UAE) is a cheap and simply equipped technology that is suitable for small and large scale production. The principle of this method is the strength effect of acoustic waves. It causes bubbles that are able to create disruption of cells, to obtain valuable compounds from plants [23]-[25].

Pressurized liquid extraction (PLE), also known as accelerated solvent extraction, is a novel treatment method with the use of high pressure and temperature to obtain compounds. When using 
water for extraction, instead of solvents, it is called subcritical water extraction. If $\mathrm{CO}_{2}$ is used for the same purpose, then the method is called supercritical or subcritical fluid extraction. But, as the method applies high pressure, it increases the cost of the equipment, leading to inefficient application [26].

Microwave-assisted extraction (MAE) uses the energy of microwaves to provide compound separation. The biggest gain from this method is the comparatively decreased use of solvents (10 to 30 millilitres) and shorter extraction time (15 to 30 minutes). The efficiency of each method is mainly dependent on the chosen sample, solvents and system (open or close vessel) used [27]. The overall scheme to get from a plant to compounds, that are ready for further use, is shown in Fig. 1.

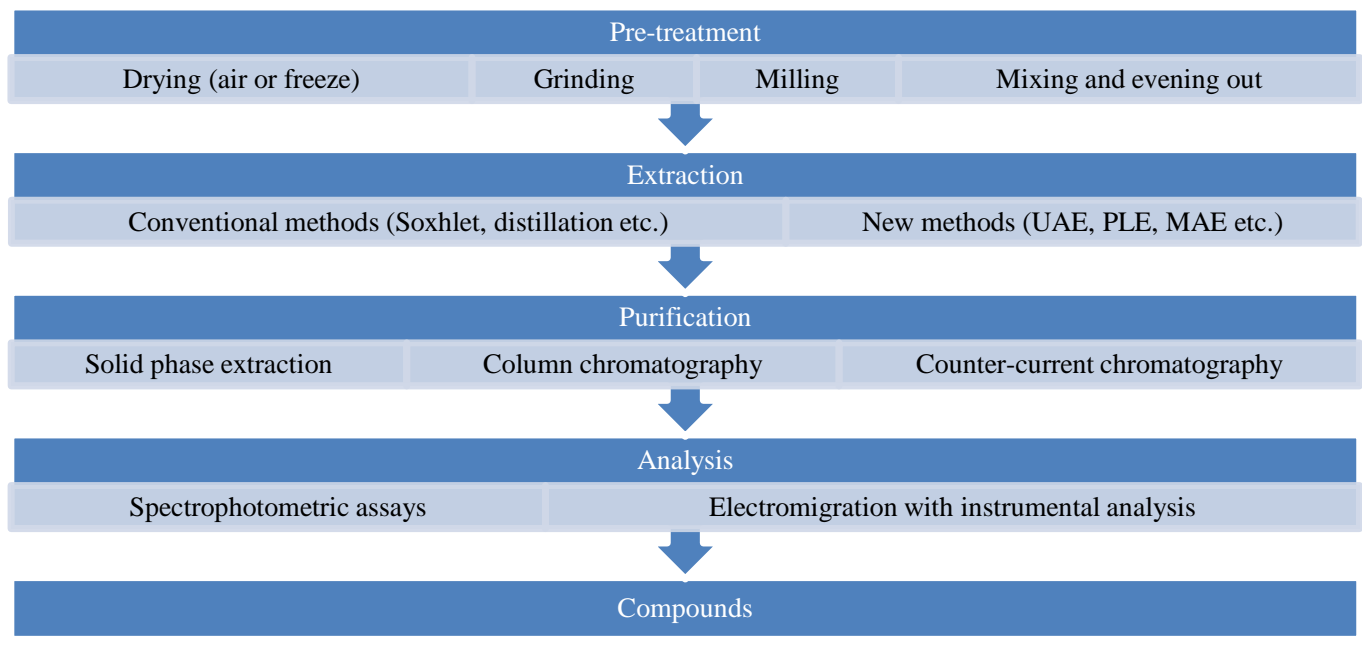

Fig. 1. Preparation of compounds from potatoes [17].

Methods used in each step are dependent on the plant that is treated. For example, in the work of Sing, et al. [19] microwave-assisted extraction, in combination with the response surface method, was used to obtain phenols from potato peels that were previously freeze dried, ground and then centrifuged. The total amount of phenolic compounds was obtained using a spectrophotometer.

\subsection{Bioplastics}

Bioplastics production in 2011 was approximately 1.2 million tons, while plastic production worldwide was 250 million tons. Therefore it is safe to say, that the bioplastics market is small. These figures can be improved by increasing the use of natural sources to produce bioplastics. In 2011 starch blends accounted for $11.3 \%$ of produced bioplastics, but from the available resources, this number can only increase [28].

Potatoes contain starch, which is one of the best and variously applicable polysaccharides. Starch consists of amylose and amylopectin. Amylose provides crystallinity and entanglement of starch, highlighting the importance of the amylose/amylopectin ratio during production and leading to improved strength and lowered strain. Starch-based bioplastic can serve as a replacement material for existing plastics, leaving no negative effects on the environment. It can be easily transformed with the already existing technologies, as the raw material is widely 
available and cheap. Plastic made from starch is compostable and can even be made into an edible product. Another alternative for using starch is thermoplastic which can be made with several technologies, such as different kinds of moulding, usually used for synthetic polymers, and casting. Elasticity can be improved by adding glycerol to the product, however it will decrease the overall strength of the material. The overall available supply of starch can be improved by the use of waste materials from production (for example, potato peels) and even genetically modified organisms [29], [30].

Bioplastics, suitable for food packaging, production of films and medicine applications, like plastic stuffs, can be made from plant proteins as well. Plants that are suitable for gluten free bioplastic production are rice and potatoes, as wheat can be dangerous to the health. Potato protein bioplastics are yet to be studied extensively. In the work of Gomez-Heincke, et al. [31] rice and potato proteins were studied as a source for bioplastics, making them in a mix with glycerol as plasticizer and wheat proteins as a reference material. It was proven that potato protein bioplastic is not affected by glycerol concentration, thermosetting for moulding, it has complex modulus value close to the one for low density polyethylene and it has resistance to higher temperatures, when compared with wheat and rice bioplastics. This plastic also showed low water absorption values $(9 \%)$, compared to wheat protein plastic, due to patatin content [31]-[33].

\subsection{Medicine and Pharmacy}

There is research devoted to the calculation of glycoalkaloid doses that effect humans. From $2 \mathrm{mg} / \mathrm{kg}$ up to $5 \mathrm{mg} / \mathrm{kg}$ of body weight of glycoalkaloids is a toxic dose, while consumption ranges of $3 \mathrm{mg} / \mathrm{kg}$ to $6 \mathrm{mg} / \mathrm{kg}$ of body weight are a lethal dose. Toxicity is highly dependent on the consumed dosage, whether it is one large dose or several small ones. Glycoalkaloids can mostly be found in the outer layer of the potato tuber and decrease towards its centre, but their amount increases during storage. However, there are benefits to be gained from these compounds, for example, it can lower cholesterol levels, reduce allergies, pains and inflammation, lower blood sugar content and lower glycogen content in livers. When used for pharmaceuticals, like cream, it can lessen damages from herpes and prevent new ones for about 9 months [8].

Most of phenolic compounds (up to $90 \%$ ) constitute chlorogenic acid that by itself is not very valuable, but it can be hydrolysed into quinic and caffeic acids. The latter shows high activity against bacteria, while quinic acid serves as a raw material for several drug syntheses. Glycoalkaloids can be found in all parts of potato plants and they can be used in pharmaceuticals, due their properties to serve as antibiotics, anti-allergens, antipyretics, anti-inflammatory and hyperglycaemic compounds at certain doses and use conditions. But these compounds have to be removed from potatoes for food production, as they can be toxic for humans, when exceeding an amount of $200 \mathrm{mg}$ per kilogram of potatoes, however most of them are reduced during processing, like cooking [8], [34]-[36].

Another product that can be made from potato peels is suberin and its monomers. It is a waxy substance that covers the outer parts of plants which is obtained from leaves as a cuticular wax, containing hydrocarbons and alcohols in a mixture with other compounds, like cholesterol. Suberin can be obtained from peels as well. Its composition and content is dependent on conditions of plant growth and other practices used. The suberized layer of potato tubers serves as additional protection against damage, infections and draught. The obtained suberin amounts are dependent on the storage time of potato tubers. The most significant amounts of raw suberin fraction gained in experiments by Jarvinen, et al. [37] were 20\%-29\% of the peel after 6 months of storage [37], 
[38]. Another research by Graca and Pereira [39] shows that suberin content in potato periderm can be approximately $25 \%$.

Starch has also been studied as a material for pharmacy product manufacturing, as it has healing abilities. Other characteristics that make starch and other potato components suitable for pharmaceuticals are their origin (natural source), biocompatibility, decomposition, formation of wax, gels and films, swelling, simple transformation. Gel-like starch is used in pharmaceuticals as binder-filler which is used in the making of tablets. Starch can also serve as an extruded material in combination with active compounds, but attention should be paid to the origin of starch, as it effects the solubility of tablets. Capsules, no matter whether they are soft or hard, that are made using potato starch as a base material, are without gelatin, are odourless, tasteless and without complications in formation and filling. Starch can also be treated as polyethylene [40].

Starch based films can serve as materials for numerous medical applications, for example, as coatings. The production of these films is closely related to the characteristics of amylose. Starch also has the potential to be used in nanotechnologies and is a preferred choice, when making medical devices, nanotubes. Other applications for starch use in the pharmaceutical industry are as binders, fillers, different coatings, capsules, decomposable substrate, implant, former and biotechnologies, that can use derivatives from starch (non-ionic and ionic compounds), obtained with methods like physical treatment, derivatization, decomposition, etherification, grafting, chemical transformations [40], [41].

Matharu, et al. [42] have proposed a biorefinery approach to produce value-added chemicals from food waste, focusing on potato and orange peels. There are about 1.3 billion tonnes of food waste created every year that can be used as a valuable resource to make novel products. The use of waste will decrease overall food waste amounts and expenses related to waste disposal, while providing value-added products to the market. Novel extraction technologies provide easy plant processing with higher efficiencies and decreased use of solvents. About $3 \%$ to $13 \%$ of grown potatoes are not used in the market due to their appearance which makes them an available source for obtaining proteins, phenolic compounds, flavonoids and other valuable contents. Potato proteins can even be recovered from fruit juice that is mostly a leftover from starch production. According to proposed approaches, protein extraction can be added to starch manufacturing, because there is no need to change existing processes, there is only a need to add a protein extraction plant. Proteins can later be used as food additives or a source for bioplastic production [42].

To further evaluate new applications of potatoes, they have to be analysed in detail. It can be done by using the methodology proposed in the work of Kubule, et al. [43]. The study offers an integrated methodology for optimization of bio-resource application, considering economic and environmental aspects.

\section{CONCLUSIONS}

According to research papers studied in the article, potatoes are an incredibly valuable source of starch, proteins, ascorbic acid, carbohydrates, minerals, vitamins and fibre, alkaloids, flavonoids, phenolic compounds. These contents provide a number of possible uses for a well-known food supply. Potatoes have proved to be applicable for use in food production, pharmacy, medicine applications and packaging. Main potato components and their possible uses are summed up in Fig. 2. 


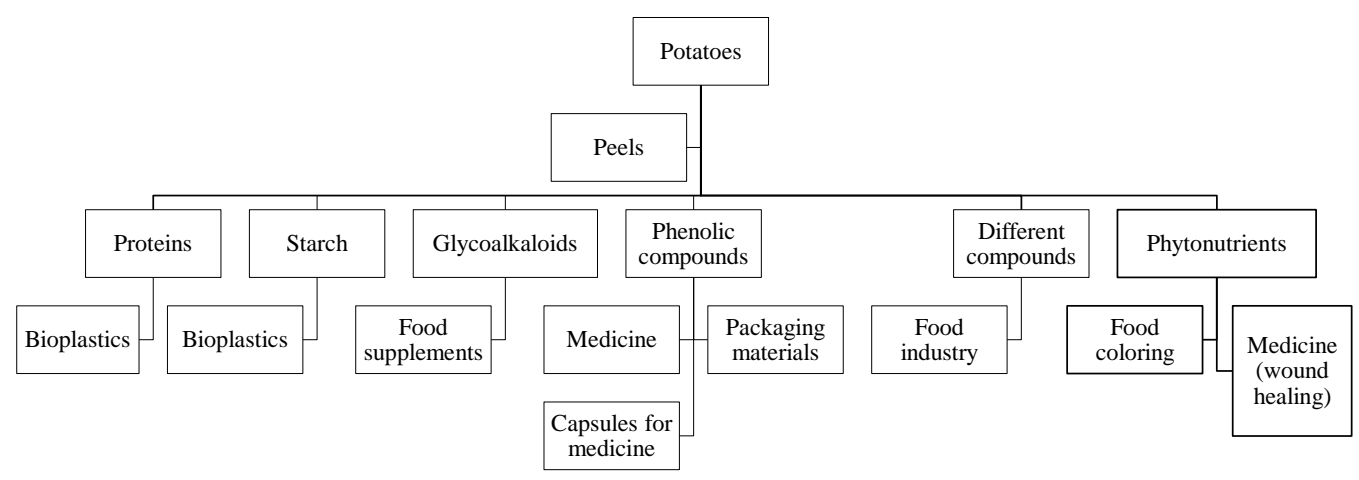

Fig. 2. Potatoes and their uses in industries.

It is possible to use potato proteins and starch to produce bioplastic with characteristics similar to low density polyethylene. Glycoalkaloids can be used as food supplements in small dosages. Phenolic compounds are suitable for use in medicine as they have numerous health improving abilities, like lowering cholesterol levels, reduction of chronic illnesses, antibacterial and antioxidant activities. They are also suitable for different packaging, such as food packaging, capsules for medicine. The use of potato compounds in the food industry is especially favourable as it is a gluten-free product with no harm to the environment.

Further research should be focused on experiments of potato use for previously mentioned purposes to see any potential improvements that are necessary to these new products and more detailed analysis on resource application optimization.

\section{REFERENCES}

[1] Barceloux D. G. Potatoes, Tomatoes, and Solanine Toxicity (Solanum tuberosum L., Solanum lycopersicum L.). Disease-a-Month 2009:55(6):391-402. doi:10.1016/j.disamonth.2009.03.009

[2] Schuler K. Solanum tuberosum (Potato). Encyclopedia of Genetics. Academic Press, 2001:1848-1850. doi:10.1006/rwgn.2001.1669

[3] Potato Facts and Figures - International Potato Center. [Online]. Available: https://cipotato.org/potato/facts. [Accessed: 09.08.2017].

[4] Kita A., Bakowska-Barczak A., Hamouz K., Kulakowska K., Lisinska G. The effect of frying on anthocyanin stability and antioxidant activity of crisps from red- and purple-fleshed potatoes (Solanum tuberosum L.). J. Food Compos. Anal. 2013:32(2):169-175. doi:10.1016/j.jfca.2013.09.006

[5] Blumberga D., Barisa A., Kubule A., Klavina K., Lauka D., Muizniece I., Blumberga A., Timma L. Biotehonomika. Riga: RTU, 2016.

[6] Glusac J., Isaschar-Ovdat S., Kukavica B., Fishman A. Oil-in-water emulsions stabilized by tyrosinase-crosslinked potato protein. Food Res. Int. 2017:100:407-415. doi:10.1016/j.foodres.2017.07.034

[7] Mahgoub H. A. M., Eisa G. S. A., Youssef M. A. H. Molecular, biochemical and anatomical analysis of some potato (Solanum tuberosum L.) cultivars growing in Egypt. J. Genet. Eng. Biotechnol. 2015:13:39-49. doi:10.1016/j.jgeb.2014.11.004

[8] Friedman M. Potato Glycoalkaloids and Metabolites: Roles in the Plant and in the Diet. J. Agric. Food Chem. 2006:54(23):8655-8681. doi:10.1021/jf061471t

[9] Rady A. M., Soliman S. N., El-Wersh A. Effect of mechanical treatments on creep behavior of potato tubers. Eng. Agric. Environ. Food 2017:10(4):282-291. doi:10.1016/j.eaef.2017.06.001

[10] Koo B.-S., Kalme S., Yeo S.-H., Lee S.-J., Yoon M.-Y. Molecular cloning and biochemical characterization of alpha- and beta-tubulin from potato plants (Solanum tuberosum L.). Plant Physiol. Biochem. 2009:47(9):761-768. doi:10.1016/j.plaphy.2009.04.001 
[11] Sanchez Maldonado A. F., Mudge E., Ganzle M. G., Schieber A. Extraction and fractionation of phenolic acids and glycoalkaloids from potato peels using acidified water/ethanol-based solvents. Food Res. Int. 2014:65:27-34. doi:10.1016/j.foodres.2014.06.018

[12] Kappachery S., Yu J. W., Baniekal-Hiremath G., Park S. W. Rapid identification of potential drought tolerance genes from Solanum tuberosum by using a yeast functional screening method. Comptes Rendus Biologies 2013:336(11-12):530-545. doi:10.1016/j.crvi.2013.09.006

[13] Friedman M., Kozukue N., Kim H. J., Choi S. H., Mizuno M. Glycoalkaloid, phenolic, and flavonoid content and antioxidative activities of conventional nonorganic and organic potato peel powders from commercial gold, red, and Russet potatoes. J. Food Compos. Anal. 2017:62:69-75. doi:10.1016/j.jfca.2017.04.019

[14] Abdel-Hafeez H. M., Saleh E. S. E., Tawfeek S. S., Youssef I. M. I., Abdel-Daim A. S. A. Utilization of potato peels and sugar beet pulp with and without enzyme supplementation in broiler chicken diets: effects on performance, serum biochemical indices and carcass traits. J. Anim. Physiol. Anim. Nutr. 2017. doi:10.1111/jpn.12656

[15] Huang W., Serra O., Dastmalchi K., Jin L., Yang L., Stark R. E. Comprehensive MS and Solid-State NMR Metabolomic Profiling Reveals Molecular Variations in Native Periderms from Four Solanum tuberosum Potato Cultivars. J. Agric. Food Chem. 2017:65(10):2258-2274. doi:10.1021/acs.jafc.6b05179

[16] Friedman M., Roitman J. N., Kozukue N. Glycoalkaloid and calystegine contents of eight potato cultivars. J. Agric. Food Chem. 2003:51(10):2964-2973. doi:10.1021/jf021146f

[17] Dai J., Mumper R. J. Plant phenolics: Extraction, analysis and their antioxidant and anticancer properties. Molecules 2010:15(10):7313-7352. doi:10.3390/molecules15107313

[18] Amado I. R., Franco D., Sanchez M., Zapata C., Vazquez J. A. Optimisation of antioxidant extraction from Solanum tuberosum potato peel waste by surface response methodology. Food Chem. 2014:165:290-299. doi:10.1016/j.foodchem.2014.05.103

[19] Singh A., Sabally K., Kubow S., Donnelly D. J., Gariepy Y., Orsat V., Raghavan G. S. V. Microwave-assisted extraction of phenolic antioxidants from potato peels. Molecules 2011:16(3):2218-2232 doi:10.3390/molecules16032218

[20] Proestos C., Komaitis M. Application of microwave-assisted extraction to the fast extraction of plant phenolic compounds. LWT - Food Sci. Technol. 2008:41(4):652-659. doi:10.1016/j.1wt.2007.04.013

[21] Singh P. P., Saldana M. D. A. Subcritical water extraction of phenolic compounds from potato peel. Food Res. Int. 2011:44(8):2452-2458. doi:10.1016/j.foodres.2011.02.006

[22] Ogutu F. O., Mu T. H. Ultrasonic degradation of sweet potato pectin and its antioxidant activity. Ultraso. Sonochem. 2017:38:726-734. doi:10.1016/j.ultsonch.2016.08.014

[23] Vinatoru M., Toma M., Radu O., Filip P. I., Lazurca D., Mason T. J. The use of ultrasound for the extraction of bioactive principles from plant materials. Ultrason. Sonochem. 1997:4(2):135-139. doi:10.1016/S1350-4177(97)83207-5

[24] Mason T. J., Paniwnyk L., Lorimer J. P. The uses of ultrasound in food technology. Ultrason. Sonochem. 1996:3(3):S253-S260. doi:10.1016/S1350-4177(96)00034-X

[25] Vinatoru M. An overview of the ultrasonically assisted extraction of bioactive principles from herbs. Ultrason. Sonochem. 2001:8(3):303-313. doi:10.1016/S1350-4177(01)00071-2

[26] Mendiola J. A., Herrero M., Cifuentes A., Ibanez E. Use of compressed fluids for sample preparation: Food applications. J. Chromatogr. A 2007:1152(1-2):234-246. doi:10.1016/j.chroma.2007.02.046

[27] Sparr Eskilsson C., Bjorklund E. Analytical-scale microwave-assisted extraction. J. Chromatogr. A 2000:902(1):227-250. doi:10.1016/S0021-9673(00)00921-3

[28] Bruder U. Bioplastics and Biocomposites. User's Guide to Plastic. Munich: Carl Hanser Verlag, 2015. doi:10.3139/9781569905739.006

[29] Sagnelli D., Hebelstrup K. H., Leroy E., Rolland-Sabate A., Guilois S., Kirkensgaard J. J. K., Mortensen K., Lourdin D., Blennow A. Plant-crafted starches for bioplastics production. Carbohydr. Polym. 2016:152:398-408 doi:10.1016/j.carbpol.2016.07.039

[30] Shah A. A., Hasan F., Hameed A., Ahmed S. Biological degradation of plastics: A comprehensive review. Biotechnol. Adv. 2008:26(3):246-265. doi:10.1016/j.biotechadv.2007.12.005

[31] Gomez-Heincke D., Martinez I., Stading M., Gallegos C., Partal P. Improvement of mechanical and water absorption properties of plant protein based bioplastics. Food Hydrocoll. 2017:73:21-29. doi:10.1016/j.foodhyd.2017.06.022

[32] Gomez-Martinez D., Partal P., Martinez I., Gallegos C. Rheological behaviour and physical properties of controlled-release gluten-based bioplastics. Bioresour. Technol. 2009:100(5):1828-1832. doi:10.1016/j.biortech.2008.10.016

[33] Mooney B. P. The second green revolution? Production of plant-based biodegradable plastics. Biochem $J$ 2009:418(2):219-232. doi:10.1042/BJ20081769

[34] Fewell A. M., Roddick J. G. Interactive antifungal activity of the glycoalkaloids $\alpha$-solanine and $\alpha$-chaconine. Phytochemistry 1993:33(2):323-328. doi:10.1016/0031-9422(93)85511-O

[35] Fewell A. M., Roddick J. G. Potato glycoalkaloid impairment of fungal development. Mycol. Res. 1997:101(5):597-603. doi:10.1017/S0953756296002973 
[36] Friedman M. Analysis of biologically active compounds in potatoes (Solanum tuberosum), tomatoes (Lycopersicon esculentum), and jimson weed (Datura stramonium) seeds. J. Chromatogr. A 2004:1054(1-2):143-155. doi:10.1016/j.chroma.2004.04.049

[37] Jarvinen R., Rauhala H., Holopainen U., Kallio H. Differences in suberin content and composition between two varieties of potatoes (Solanum tuberosum) and effect of post-harvest storage to the composition. LWT - Food Sci. Technol. 2011:44(6):1355-1361. doi:10.1016/j.lwt.2011.02.005

[38] Szafranek B. M., Synak E. E. Cuticular waxes from potato (Solanum tuberosum) leaves. Phytochemistry 2006:67:80-90. doi:10.1016/j.phytochem.2005.10.012

[39] Graca J., Pereira H., Suberin Structure in Potato Periderm: Glycerol, Long-Chain Monomers, and Glyceryl and Feruloyl Dimers. Journal of Agricultural and Food Chemistry 2000:48(11):5476-5483. doi:10.1021/jf0006123

[40] Outline C. Starch and derivatives as pharmaceutical excipients. Control. Drug Deliv. 2015:21-84.

[41] Lu D. R., Xiao C. M., Xu S. J. Starch-based completely biodegradable polymer materials. Express Polym. Lett. 2009:3(6):366-375. doi:10.3144/expresspolymlett.2009.46

[42] Matharu A. S., de Melo E. M., Houghton J. A. Opportunity for high value-added chemicals from food supply chain wastes. Bioresour. Technol. 2016:215:123-130. doi:10.1016/j.biortech.2016.03.039

[43] Kubule A., Komisarova T., Blumberga D. Optimization methodology for complete use of bio-resources. Energy Procedia 2017:113:28-34. doi:10.1016/j.egypro.2017.04.009

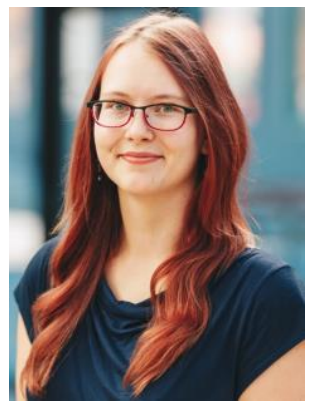

Vivita Priedniece has received B. sc. degree from Riga Technical University (RTU) in 2013. She is on her 2nd year of masters in Environmental Science, RTU.

Author is working at Riga Technical University in the Institute of Energy Systems and Environment as a Scientific Assistant. Current research is related to flue gas cleaning fog unit. Previous publications include:

1. Vivita Priedniece, Toms Prodanuks, Mohamed Marwan Fawzy, Valters Kazulis, Ivars Veidenbergs, Dagnija Blumberga. Biomass co-firing laboratory equipment. Energy Procedia https://doi.org/10.1016/j.egypro.2017.04.019.

2. Haralds Vigants, Vivita Priedniece, Ivars Veidenbergs, Dagnija Blumberga. Process optimization for pellets production. Energy Procedia https://doi.org/10.1016/j.egypro.2017.04.021.

3. Jevgenijs Selivanovs, Edgars Vigants, Vivita Priedniece, Ivars Veidenbergs, Dagnija Blumberga. Flue gas treatment multi-criteria analysis. Energy Procedia https://doi.org/10.1016/j.egypro.2017.09.056.

E-mail: vivita.priedniece@rtu.lv
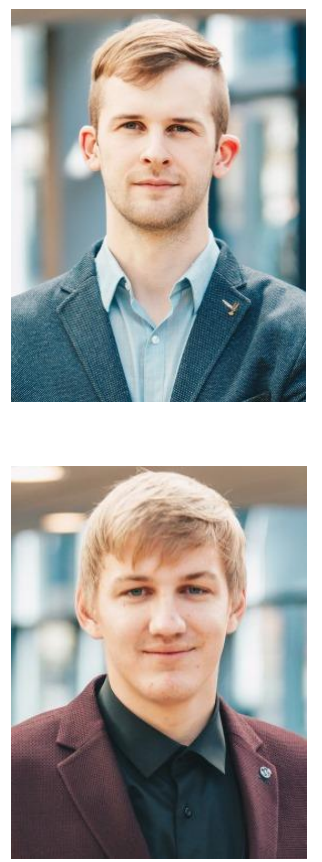

Kriss Spalvins (Ms. biol.) is $\mathrm{PhD}$ student in Environmental Engineering at the Riga Technical University. He received Bachelor's degree of Natural Sciences in biology at University of Latvia in 2014 and Master's degree of the same specialty in 2016. Work experience includes: Researcher at Institute of Energy Systems and Environment located at Azenes iela 12/1, Riga, Latvia; Natural Science assistant (Internship) in University of Regensburg, Regensburg (Germany), Department of Cell Biology and Plant Biochemistry. He developed his Bachelor's thesis in Department of Plant Physiology (University of Latvia) where he worked on research of vermicompost effects on growth and development of various cultivated plants. During his internship in University of Regensburg he developed his Master's thesis where he researched defensin-like genes and ovule development of the flowering plant Arabidopsis thaliana. Current research focuses on use of biodegradable waste in cultivation of various oleaginous and protein rich microorganisms. ORCID: https://orcid.org/0000-0003-4464-1101

Kaspars Ivanovs, M. sc. ing., Riga Technical University (RTU). He received Master's degree in Environmental Science at University of Latvia. He is continuing Environmental Engineering PhD studies Riga Technical University. Work experience includes: Researcher at Institute of Energy Systems and Environment located at Azenes iela 12/1, Riga, Latvia. Senior fisheries inspector at the State Environmental Service of the Republic of Latvia and assistant at Institute of Food Safety, Animal Health and Environment - "BIOR". Previous research interests include feeding ecology of carnivorous fishes, ecology of freshwater lakes. Current research focuses in use of fish waste in order to manufacture products with higher added value.

E-mail: Kaspars.Ivanovs@rtu.lv

ORCID: https://orcid.org/0000-0003-4700-3172 


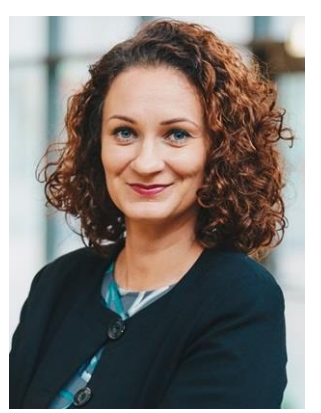

Jelena Pubule, Dr. sc. ing., Docent and Senior researcher at Riga Technical University, Institute of Energy Systems and Environment. Since 2008 Jelena Pubule is working at Riga Technical University. The main research area of the Author is environmental impact assessment, waste management and application of circular economy in different economic sectors. She has actively contributed to research articles in various international journals and conferences. She has been involved in several environmental research projects at local and international level related to integration of renewable energy sources in energy systems. Jelena Pubule is an expert of Latvian academy of science.

E-mail: jelena.pubule@rtu.lv.

ORCID: https://orcid.org/0000-0002-0373-2675

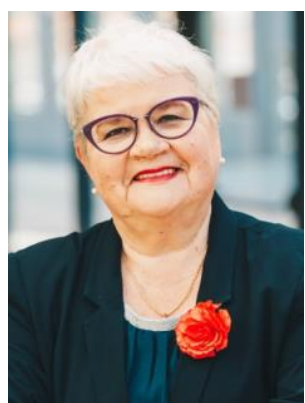

Dagnija Blumberga, Dr. habil. sc. ing., professor, director of the Institute of Energy Systems and Environment, Riga Technical University. Her two-step doctoral degree "Condensing Unit" was defended in Lithuanian Energy Institute, Kaunas (1988). Doctor Habilitus Thesis "Analysis of Energy Efficiency from Environmental, Economical and Management Aspects" was prepared in Royal Institute of Technology (KTH) Stockholm (1995) and was defended in Riga Technical University (1996).

Dagnija Blumberga has been part of academic staff of Riga Technical University since 1976 and director of Institute of Environmental Protection and Energy Systems since 1999.

The main research area is renewable energy resources. She has participated in different local and international projects related to energy and environment as well as an author of more than 200 publications and 14 books.

ORCID: https://orcid.org/0000-0002-9712-0804 